\title{
Novel Mango Ginger Bioactive (2,4,6-trihydroxy-3,5- diprenyldihydrochalcone) Inhibits Mitochondrial Metabolism in Combination with Avocatin B
}

Varsha Jayasankar ${ }^{1}$, Nikolina $\operatorname{Vrdoljak}^{1}$, Alessia Roma ${ }^{1}$, Nawaz Ahmed ${ }^{1}$, Matthew Tcheng ${ }^{1}$, Mark D. Minden ${ }^{2}$, and Paul A. Spagnuolo ${ }^{1 *}$

${ }^{1}$ Department of Food Science, University of Guelph, 50 Stone Rd. Guelph Ontario, Canada. N1G2W1

${ }^{2}$ University Health Network, 610 University Ave, Toronto, ON, CAN M5G 2C4

* Correspondence:

Paul A. Spagnuolo, Ph.D.

Associate Professor, Department of Food Science

University of Guelph

Guelph, Ontario, N1G 2W1

Phone: (519) 824-4120 x53732

paul.spagnuolo@uoguelph.ca 


\section{Supplementary Information}

\section{Part 1: Methods}

\section{Avocatin B Extraction}

Hass avocado seeds were air dried, crushed and placed in glass bottles with ethyl acetate in a 2:1 solvent: seed ratio. The bottles were sealed and rotated on a $120 \mathrm{Vac}$ Benchtop Roller (Wheaton; Millville, NJ) for 24 hours. Extracts were then gravity filtered and the solvent was evaporated using a Rotavapor ${ }^{\circledR}$ R-100 rotary evaporator (BÜCHI Labortechnik AG, Flawil, Switzerland) twice. The crude extract was purified using flash chromatography using a silica (Fisher Scientific; Mississauga, ON) column and ethyl acetate as the mobile phase. Column fractions were analyzed for purity using thin layer chromatography (eluent: ethyl acetate, $R_{f}=0.30$ ) and visualized using $p$ anisaldehyde stain (Fisher). All purified samples were characterized by ${ }^{1} \mathrm{H}$ NMR. Samples were dissolved to $2 \mathrm{mg} / \mathrm{mL}$ in deuterated chloroform $\left(\mathrm{CDCl}_{3}\right)$ and transferred to an NMR tube. The samples were then analyzed using an Avance $400 \mathrm{MHz}$ 
spectrometer (Bruker; Billerica, Massachusetts) and recorded as parts per million (ppm).

Purified Avo B was dissolved in DMSO for experimental use.

\section{Combination Index Calculations}

CI values were calculated using the Chou-Talalay Combination Index Method, using

the following formula based on the based on the median-effect equation

$$
C I=\frac{(D)_{1}}{\left(D_{x}\right)_{1}}+\frac{(D)_{2}}{\left(D_{x}\right)_{2}}
$$

where $(D x)_{1}$ is a concentration of the first drug individually that inhibits a system by $\mathrm{x} \%$, and $(\mathrm{Dx})_{2}$ is a concentration of the second drug individually that inhibits a system by the same $x \%$. The numerator, $(D)_{1}$ and $(D)_{2}$, are the drug concentrations in the combination that also inhibit $\mathrm{x} \%$.

\section{Respirometry}

\section{Cell Culture}

Cell viability was determined using trypan blue $0.4 \%$ cell stain (Gibco) and counting using a hemocytometer. Cells with $\geq 95 \%$ viability were used for cell culture. OCI-AML2 and OCI-AML3 cells were cultured in $100 \mathrm{~mm}$ cell culture dishes (Corning) at a density 
of $0.5 \times 10^{6}$ cells $/ \mathrm{mL}$ in $10 \mathrm{~mL}$ of IMDM media; 10 million cells were required for each treatment. The desired treatment $(1 \mu \mathrm{M} \mathrm{M} 1,2 \mu \mathrm{M}$ Avo $\mathrm{B}, 1 \mu \mathrm{M} \mathrm{M} 1+2 \mu \mathrm{M}$ Avo $\mathrm{B}$, or DMSO) was added and the plates were incubated in $5 \% \mathrm{CO} 2$ at $37^{\circ} \mathrm{C}$ for 1 hour.

\section{Permeabilization}

After incubation, the cells required for 1 treatment were collected and centrifuged at $1200 \mathrm{rpm}$ for 5 minutes. The media was then removed, and the pellet was resuspended in $1 \mathrm{~mL}$ of PBS. The pellet was then transferred to a $1.5 \mathrm{~mL}$ microcentrifuge tube and centrifuged at $1200 \mathrm{rpm}$ for 5 minutes in a microcentrifuge. Following the second centrifugation, the PBS wash was carefully removed, and the pellet was suspended in $500 \mu \mathrm{L}$ permeabilization buffer $(80 \mathrm{mM} \mathrm{KCl}$ and $250 \mathrm{mM}$ sucrose in PBS) containing 0.01\% digitonin (Sigma-Aldrich). The mixture was then agitated gently for 3 minutes, centrifuged at $1200 \mathrm{rpm}$ for 5 minutes, and recentrifuged for one more cycle after the permeabilization buffer was removed. The pellet was then suspended in $150 \mu \mathrm{L}$ of MiR05 respiration buffer and injected into the Oroboros Oxygraph-2k (Oroboros Instruments; Innsbruck, Austria) chambers. The Oroboros Oxygraph-2k chambers 
contained $2 \mathrm{~mL}$ of MiR05 mitochondrial respiration medium (0.5mM EGTA, $3 \mathrm{mM} \mathrm{MgCl}$,

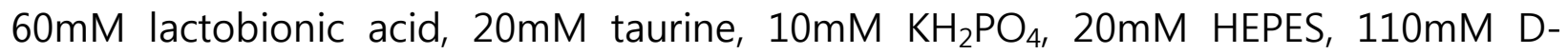
sucrose, $1 \mathrm{mg} / \mathrm{mL}$ bovine serum albumin (BSA) in $\mathrm{dd}_{2} \mathrm{O}$ ) [93]. Basal respiration was measured after injection, once steady-state respiratory flux was obtained.

\section{Electron Transport Chain Activity}

\section{Mitochondria Rich Fraction Preparation}

Using AML2 cells, $15 \times 10^{6}$ cells were collected and centrifuged for 5 minutes at 1200 rpm. The cells were washed with $1 \mathrm{~mL}$ PBS for 5 minutes at $1200 \mathrm{rpm}$; the supernatant was discarded, and the pellet was retained. The pellet was then flash frozen in liquid nitrogen, thawed on ice, and resuspended in $10 \mathrm{mM}$ of ice-cold hypotonic Tris $\mathrm{HCl}$ buffer. The cells were homogenized with 3 pulses on Fisherbrand Model 120 Sonic Dismembrator (Fisher Scientific), with each pulse consisting of 3 seconds on, 3 seconds off at $45 \%$ amplitude. The cell homogenate was mixed thoroughly with $200 \mu \mathrm{L}$ of a $1.5 \mathrm{M}$ sucrose solution and centrifuged at $600 \mathrm{~g}$ for 10 minutes at $2^{\circ} \mathrm{C}$ using a microcentrigue. The supernatant was then collected in a $1.5 \mathrm{~mL}$ microcentrifuge tube 
and centrifuged at $14000 \mathrm{~g}$ for 10 minutes at $2{ }^{\circ} \mathrm{C}$. The supernatant was discarded, and the pellet was resuspended in $150 \mu \mathrm{L}$ of $10 \mathrm{mM}$ ice-cold hypotonic Tris $\mathrm{HCl}$ buffer and divided into aliquots for protein estimation.

\section{BCA Assay}

The total protein content of the mitochondria fraction was quantified using the BCA protein assay. BSA standards at $0,20,40,60,80$, and $100 \mu \mathrm{g} / \mathrm{mL}$ were created and $10 \mu \mathrm{L}$ of each standard was plated in triplicate in a 96-well plate. The mitochondrial rich fraction was diluted $10 \mathrm{x}$ using $\mathrm{ddH}_{2} \mathrm{O}$, and $10 \mu \mathrm{L}$ of this dilution was added to the 96-well plate in triplicate. Bicinchoninic acid (BCA) working reagent was then prepared containing 50 parts BCA (Sigma-Aldrich) to one-part 4\% copper II sulphate (SigmaAldrich). The BCA working reagent was added to each BSA standard and sample well in the 96-well plate. The optical density was measured at 527nm using the Synergy HT spectrophotometer. Protein content of the sample was estimated using the standard curve. 


\section{Supplementary Figure 1}
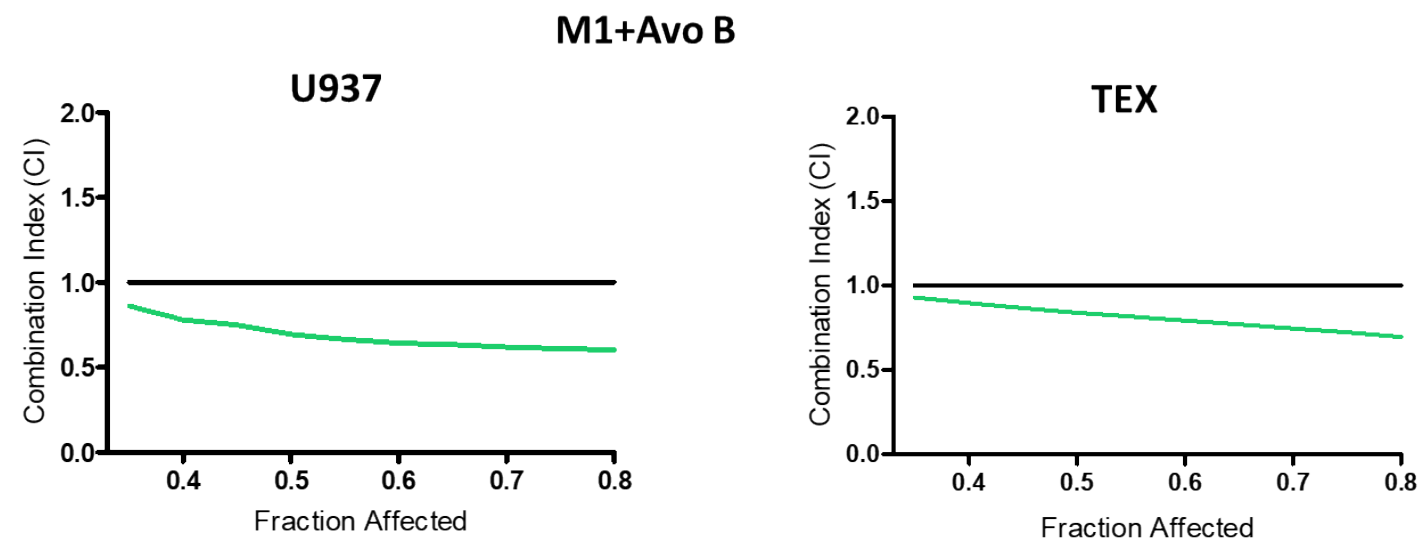

Figure S1: M1 interactions with Avo B in U937 and TEX cells. Equal molar concentrations of M1 and Avo B were incubated with U937 (left) or TEX (right) leukemia cells and cell viability was measured after $72 \mathrm{~h}$ by flow cytometry using 7AAD. Combination index (CI) values, which assesses drug-interaction effects, were calculated using the CompuSyn software. CI values of $<1$, $>1$ or equal to 1 denote statistical synergy, antagonism, or additivity, respectively. All experiments are $n=3$, data is mean $\pm S D$. Representative figures shown. 